\title{
1. Transparency in EU procurements: an introduction
}

\author{
Kirsi-Maria Halonen, Roberto Caranta and \\ Albert Sanchez-Graells
}

It follows from the CJEU case law that transparency is a general principle of EU public procurement law or at least a corollary of the general - and foundational - principle of non-discrimination. While this starting point is indisputable, how transparency translates into the rules and practices of procurement of the EU institutions and in the Member States varies very significantly.

Harmonisation by the EU public procurement and concessions directives goes at times into much detail. This is for instance the case with the publication and content of the notice starting most contract award procedures. But much is left to the Member States while EU institutions apply discretely different rules. For instance, rules concerning access to documents of the award procedure and to the concluded contract are very scant or not given at all, and this is the case even if the remedies directives are taken into consideration.

Therefore the rules themselves, and the actual level of openness, end up diverging considerably because of the different traditions concerning transparency in the Member States. In many EU jurisdictions, transparency is considered as a starting point regarding all public information and public sector activities. Others, however, have only very slowly warmed to the idea of subjecting documents held by the public sector to 'on request' disclosure or, even more, to disclosure motu proprio.

The actual rules on transparency in public procurement end up being defined by the combination of EU rules and case law, with the Member States general - and at times constitutional - and procurement specific rules setting the level of openness considered to be optimal. The same applies to EU institutional procurement. Specific rules are to be read in conjunction with Treaty rules, including those in the Charter of Fundamental Rights of the EU. In turn these are applicable - or influence the rules applicable - to procurements in the Member States.

To go beyond generalisations and to provide an accurate picture of transparency in both EU institutional procurements and in those of the Member States, 
this book analyses in detail the legislation and practice in ten jurisdictions. Besides EU institutional procurements, Denmark, Finland, France, Germany, Italy, Poland, Romania, Spain and the UK are covered.

Contributors answered a questionnaire which is reproduced at the end of this short introduction. After providing some background to the position of transparency within the public law and procurement architecture of their jurisdiction, contributors were asked to sketch the general framework for transparency, to analyse ex ante and ex post transparency, and finally to comment on transparency in litigation and oversight. The contributions are structured in the same order as the questionnaire and authors have indicated the correspondence between their analysis and the questionnaire by adding the relevant question number between parenthesis at the beginning of the appropriate paragraph. This will make comparisons across jurisdictions easier, as the reader interested in a specific issue will be able to easily locate the relevant parts of each jurisdictional analysis. Readers aiming for a more comprehensive analysis can simply disregard those notations.

Based on these reports, and on independent EU and comparative law research, the editors contributed three cross-cutting chapters. The first, by Kirsi-Maria, gives a broad and critical picture of the different approaches to openness in the Member States, looking for their causes in the legal traditions of the Member States. The chapter also highlights the problems these differences pose to economic operators tendering for contracts in different Member States. The chapter by Albert provides some comparative reflections on the need for public procurement systems to reach an adequate balance between their transparency requirements and the risks of collusion among tenderers, or bid rigging. Finally, Roberto investigates how judicial protection is affected by different takes on transparency and openness providing interesting insight and analysis on what level of transparency is actually required in order to comply with the requirement of l'effet utile of EU law.

Taken together, the chapters in this book expose the fallacy of thinking we know everything about transparency in public procurement. Quite to the contrary, major questions are still open and are awaiting solutions at both EU and national level. We are confident our book provides not just food for thought, but also points to some answers, including in view of prospective reform of EU (and national) law.

\section{QUESTIONNAIRE}

\section{Introduction}

Please use this to provide a short overview of the system in your jurisdiction, including a short account of the competence allocation (State, region, local 
level) and some consideration of the general tradition or starting point on transparency/opacity of public sector information (e.g., is the first approach that all public documents are public or the opposite). Where relevant, please indicate if there have been any meaningful changes as a result of EU law influence. Please consider whether there is any on-going initiative linked to the European Commission's plan to support the development of national procurement transparency registers as part of the 2015 Strategy for the Upgrade of the Internal Market (para 3.2, https://ec.europa.eu/transparency/regdoc/rep/1/2015/EN/1 -2015-550-EN-F1-1.PDF). Also have a look to the approach taken in http:// digiwhist.eu/.

\section{General Framework for the Regulation of Transparency in Procurement}

(1) Are there general public law rules imposing transparency/access to documents that affect procurement? Is there a distinction between documents and information contained in the documents? If the rules are on access to documents, does this apply to both draft and final documents, or only to final documents? If so, how does this play out in terms of partial access to documents (i.e., blacked out or confidential versions? If there are general rules on transparency, do they apply to all procurement activities or only to those carried out by public authorities (*please note the difference between public authorities and contracting authorities here)? If the general rules do not apply to all procurement activities (e.g., they do not cover bodies governed by public law), is there discussion of the need to extend them to cover all procurement (e.g., procurement by private-form entities, such as CPBs organised as limited liability companies)? Who has the right to use these general rules (e.g., who is a party or entity with an interest, or can anyone access - are there different levels of access depending on whether someone is recognised as an affected party by a document)? Are there any time limits to request access to documents? Are there any time limits for the disclosure of documents after the request (e.g., ten working days)? If so, which are those limits?

(2) What are the specific rules establishing transparency in procurement? What is/are the main goal/s they aim to protect?

(3) Has the interplay between general transparency law and procurement transparency and any of the conflicting goals (good governance, competition, business secrets, access to remedies) been explicitly addressed in either statutory instruments, case law or administrative practice? How has this balance been described (if there is a large number of case law, could you please select the most relevant cases (two to three) of the highest instance in the jurisdiction)? How do these rules interact with data protection (i.e., privacy) rules where individuals' information is contained in procurement documents? Can 
you provide a sense of whether there are procedural strategies to benefit from general rules over procurement specific rules, or the other way around e.g., in practice, do lawyers recommend to their clients to use freedom of information (FOI) requests, or do they rather resort to procurement specific mechanisms)?

\section{Ex ante Procurement Transparency}

Please note that this section is mainly concerned with documents produced by the contracting authority to design the procurement process. Issues concerning the tenderers' bids are mainly covered in the following section.

(4) Is there a single database/portal for contract notices, or are there different platforms that can be used by contracting authorities? Is the relevant database connected with TED? Are there national rules requiring publication of contract notices and/or call for tenders on contracts below EU thresholds? If so, please explain whether the rules are the same as those for above thresholds procurement or, on the contrary, please make any differences as clear as possible.

(5) Are draft contracts and other relevant documentation published in full, or are they only made accessible to interested tenderers after they express their intention to bid? Is there a charge for the access to that information? If so, is this a violation of the 2014 rules requiring free access save for exceptional circumstances?

(6) Do contracting authorities exercise the power to declare all or part (e.g., technical specs) of tender documents confidential? Can you give a sense of whether this is common practice? If this is common practice in some specific sector (e.g., technology or defence), or in relation to specific procedures (e.g., competitive dialogue or innovation partnerships), please provide as much detail as possible.

(7) Are the CAs required to publish other documentation than contract notices and call for tender in open access format electronically? Is there any 'big data' requirement in terms of allowing for data mining or other automated data treatment procedures (in terms of format of the information, inclusion of metadata, etc), or are scanned pdfs used?

(8) Are contracting authorities required to publish an estimate of the cost of the procurement? If so, is that estimate accessible to interested tenderers? Is it accessible to third parties? Please bear in mind that this is in principle required by EU standard notice templates, so in case of deviation from the templates, please explain why.

(9) Are the CAs required to disclose in advance the matrix/calculation method they plan to use to evaluate tenders against the MEAT? If so, do they have to publish it for everyone to see or only disclose it to interested tenderers? Is there a standard methodology or matrix, or is the common practice of 
contracting authorities to not structure their evaluations through the use of a matrix?

(10) What are the rules on voluntary ex ante (VEAT) notices regulated in the remedies directive (Art $2 \mathrm{~d}$, paragraph 4 )? Is it common practice to publish VEAT notices?

\section{Ex post Procurement Transparency}

Please note that this section is mainly concerned with two types of documents: (i) tenderers' bids (including technical and financial information) and (ii) evaluation documents prepared by the contracting authority.

(11) Disclosure of tender evaluation documents:

(11.a) what does national law require to be included in the award decision? In case of negotiations, does the award decision have to document the progress in the negotiations and the final conditions of the contract? Are negotiation documents otherwise accessible to the tenderers? Are documents accessible only to the party involved in the negotiation, or to all tenders? In general, what is the transparency/access to documents prepared as a result of Article 84.2 of the Directive?

(11.b) Are the full tender evaluation documents disclosed to tenderers after the award decision? Points and written reasoning? Is there access to drafts or only to final evaluation documents? Is the specific evaluation under the matrix detailed in the justification, or are only overall/per criterion points disclosed? Do tenderers have access to their own evaluation only, or also to those of other tenderers? If there is access to other tenderers' evaluation, does this cover access to the entirety of the evaluation report, or only to some parts of it/ condensed information?

(11.c) Third-party access: does anyone (third parties, individuals, journalists, etc.) have access to award decisions, to the evaluation documents or to any negotiation documents/minutes?

(12) Do the tenderers have access to each other's tenders (after the award decision has taken place for the purposes of verifying whether there are grounds for appeal/application for judicial review)? In particular, do tenderers have access to each other's pricing information? If so, what level of detail (e.g., unit prices, or total prices only, or price brackets, etc).

(13) Do third parties have access to the tenders submitted after the award decision and before the signature of the contract? If not before the signature of the contract, do they have access to the tenders once the contract is signed?

(14) Do other tenderers have access to a procurement contract after it is concluded with the winning bidder? If the final signed contract is not accessible, please indicate whether any deviations from the draft contract (see (5) above) need to be somehow disclosed or mentioned in publicly-accessible documents. 
(15) Do third parties have access to a procurement contract after it is concluded with the winning bidder? If the final signed contract is not accessible, please indicate whether any deviations from the draft contract (see (5) above) need to be somehow disclosed or mentioned in publicly-accessible documents.

(16.a) Is commercial/industrial secret any limit to tenderers' or third parties' right of access to information included in the tenders or in the contract? How is this defined? Can you please discuss the most important two to three cases on limits to disclosure on the basis of commercial interests or business secrets? Is there a presumption of confidentiality or of public access? Who bears the burden of proof to deactivate the presumption? What are the consequences for contracting authorities and/or their servants if they improperly disclose confidential information? What are the consequences if they reject the disclosure of information that was not really confidential? Is there a specific procedure (or stage in the procedure) to deal with confidentiality issues? Who can participate in any such stage or discussions? Must the contracting authority consult the party whose business secrets or commercial interests may be affected? Does the contracting authority have any duty to protect those interests ex officio or motu proprio?

(16.b) Is there a perception that transparency or any other characteristics of procurement markets create risks of distortion of competition/cartellisation? Can contracting authorities reject disclosing information to avoid distortions of competition (they must under the directive, Article 55, so if the answer is negative, please clarify why)? Do they regularly do it? Do they collaborate with the competition authority to assess these types of issues? Is the competition authority active in the prevention of cartels in public procurement markets? Have there been any relevant cases in the last five years of cartels in procurement markets (e.g., asphalt cases in Finland and Sweden)?

(17) Does national law impose wider obligations to CAs to publish information on contract amendments than what is required under EU Directive?

(18) Do third parties/other tenderers have access to information on the bills/ orders/order confirmations etc. during the contract execution? Is this part of a national registry or any other platform accessible by the public? Is there an obligation to feed information into that platform (e.g. Italy or Portugal) or is this voluntary (e.g., Finland)?

(19) Are/Is any of the documents/information above available on the web?

\section{Transparency in Procurement Litigation and Procurement Oversight}

Please provide a very short explanation of the review mechanisms, and whether they are administrative (e.g., complaints board) or judicial, and whether dif- 
ferent procedural rules apply to each of them. In judicial procedures, please clarify whether they are public/administrative or rather civil/commercial.

(20) Are the access rights to any procurement documentation different if documents are requested from a court during a procurement dispute (and not from the CA as such) under national procedural rules? If there is no pre-litigation access to documents, can complaints or appeals be lodged 'blindly' and, if so, do the review bodies have an obligation to investigate and, if so, a further obligation to let the applicant access the documents? How long does it take? Are national procedural rules on fact finding/investigation different from the rules protecting right to access, and if so how do the two bodies of rules interact? Would the courts have access to more documents than the parties (i.e., the Varec situation) and, if so, does the court then have a duty or a prohibition (or anything in between) to share that information with the parties? Is the concept of party different for the purposes of litigation and for other purposes (e.g., the access to freedom of information/general transparency rules, see question (1))? Are there confidentiality obligations and/or confidentiality agreements binding the parties that have access to that information? What would be the penalties or consequences of breaching such confidentiality obligations/agreements? Is there any restriction on the use you can make of the information you gain through this mechanism? How is that monitored? What are the consequences for a breach?

(21) Do the rules differ in the event where a case is handled by a Complaints Board/Review Board if any?

(22) Is there case law or administrative practice concerning the treatment of confidential information and the tenderers' rights to oppose disclosure? Please discuss the main cases.

(23) Are there any national rules requiring the CAs or contractors to submit certain information to national procurement monitoring authorities? Can those authorities request information on specific cases, or solely on general trends (e.g. statistics)? What is the delay in this monitoring activity? Do contracting authorities have an obligation to submit this information or must they only do this on request? Do these authorities have unlimited access to information? 